\section{BMJ Open}

Ophthalmology

\title{
Role of amyloid $\beta$-peptide in the pathogenesis of age-related macular degeneration
}

\section{Minwei Wang (D) , ${ }^{1}$ Shiqi Su, ${ }^{2}$ Shaoyun Jiang, ${ }^{3}$ Xinghuai Sun, ${ }^{4}$ Jiantao Wang ${ }^{5}$}

To cite: Wang M, Su S, Jiang S, et al. Role of amyloid $\boldsymbol{\beta}$-peptide in the pathogenesis of agerelated macular degeneration. BMJ Open Ophthalmology 2021;6:e000774. doi:10.1136/ bmjophth-2021-000774

Received 30 March 2021 Accepted 18 June 2021

\section{Check for updates}

\section{(C) Author(s) (or their} employer(s)) 2021. Re-use permitted under CC BY-NC. No commercial re-use. See rights and permissions. Published by BMJ.

${ }^{1}$ Department of Biochemistry and Biophysics, University of California San Francisco, San Francisco, California, USA ${ }^{2}$ Department of Anatomy and Neurobiology, University of California Irvine, Irvine, California, USA

${ }^{3}$ Stomatological Center, Peking University Shenzhen Hospital, Shenzhen, Guangdong, China ${ }^{4}$ Fudan University Eye Ear Nose and Throat Hospital, Shanghai, China

${ }^{5}$ Shenzhen Eye Hospital, Shenzhen, Guangdong, China

Correspondence to Jiantao Wang; wangjianta065@ 126.com

\section{ABSTRACT}

Age-related macular degeneration (AMD) is the most common eye disease in elderly patients, which could lead to irreversible vision loss and blindness. Increasing evidence indicates that amyloid $\beta$-peptide $(A \beta)$ might be associated with the pathogenesis of AMD. In this review, we would like to summarise the current findings in this field. The literature search was done from 1995 to Feb, 2021 with following keywords, 'Amyloid $\beta$-peptide and age-related macular degeneration', 'Inflammation and age-related macular degeneration', 'Angiogenesis and age-related macular degeneration', 'Actin cytoskeleton and amyloid $\beta$-peptide', 'Mitochondrial dysfunction and amyloid $\beta$-peptide', 'Ribosomal dysregulation and amyloid $\beta$-peptide' using search engines Pubmed, Google Scholar and Web of Science. $A \beta$ congregates in subretinal drusen of patients with AMD and participates in the pathogenesis of AMD through enhancing inflammatory activity, inducing mitochondrial dysfunction, altering ribosomal function, regulating the lysosomal pathway, affecting RNA splicing, modulating angiogenesis and modifying cell structure in AMD. The methods targeting $A \beta$ are shown to inhibit inflammatory signalling pathway and restore the function of retinal pigment epithelium cells and photoreceptor cells in the subretinal region. Targeting $A \beta$ may provide a novel therapeutic strategy for AMD.

\section{INTRODUCTION}

Age-related macular degeneration (AMD) has been regarded as the leading cause of progressive central vision loss and blindness in the elder individuals due to the impairment of photoreceptor cells (PRCs) and retinal pigment epithelium (RPE) cells caused by the formation of drusen in Bruch's membrane and the growth of leaky blood vessels beneath the retina. ${ }^{1-4}$ In the past 10 years, considerable attention has been paid to the significant role of oligomeric amyloid $\beta$-peptide $(\mathrm{A} \beta)$ in the developed pathogenesis of AMD. A $\beta$ comprises peptides between 39 and 43 amino acid residues which are produced by the proteolytic cleavage process of amyloid precursor protein (APP) with the utilisation of multisubunit enzyme complex and membrane-bound aspartyl protease..$^{5-7}$
Previous studies suggested that oligomeric $\mathrm{A} \beta$ has been crucially involved in the pathogenesis of Alzheimer's disease (AD). Under conditions with $A \beta$, microglia could be stimulated and activated chronically, which leads to extensive neuronal apoptosis. Moreover, aggregation of $A \beta$ could induce the dysfunction of microtubules associated protein-2, which successively disrupts the microtubules structure and process of axonal transport. ${ }^{8}$ $\mathrm{A} \beta$ can also disrupt the glucose metabolism in the brain by vying with insulin for binding to its receptor. ${ }^{9}$ Increasing evidence indicates that $\mathrm{AD}$ and $\mathrm{AMD}$ share similar pathophysiological features, such as neuroinflammation and oxidative stress. ${ }^{10}{ }^{11} \mathrm{~A} \beta$ has been affirmed to be specifically prevalent in the extracellular soft drusen deposits of patients with AMD. ${ }^{12-14}$ Administration of $\mathrm{A} \beta$ in the subretinal region of $\mathrm{C} 57 \mathrm{BL} / 6$ mice has shown similar pathology with AMD which exacerbates the senescence of RPE cells and retinal degeneration, suggesting that $A \beta$ may be responsible for the characteristics of AMD. ${ }^{15}$ Recent studies have identified multiple different isoforms of $A \beta$, 40-residue peptide $\mathrm{A} \beta$ (1-40) and 42-residue peptide $\mathrm{A} \beta$ (1-42), which were the major constituents of drusen deposits in the subretinal space of patients with AMD. ${ }^{16} 17$ The overexpression of $\mathrm{A} \beta$ (40-residue and 42-residue) leads to the formation of drusen-like deposits in subretinal space in the eye and produces RPE atrophy. ${ }^{13161819}$ Moreover, senescent models with $A M D$ present increasing amount of $A \beta$ drusen in outer segments layer, leading to the outcome of PRCs loss and aberrant localisation of RPE cells. ${ }^{520}$ Several pathways involved in $A \beta$ enhancing the formation of AMD have been clarified in current researches.

\section{$A \beta$ induces inflammasome in AMD}

Inflammatory activity is a rapidly deteriorating mechanism and induced by several stress factors such as increased oxidative stress and decreased proteostasis, which has been tightly 
related to the pathogenesis of AMD. ${ }^{21}{ }^{22}$ Previous evidence has shown that $\mathrm{A} \beta$-induced inflammatory activity has a significant impact on the pathology of AMD and could be induced in distinct pathways. ${ }^{21}$ In the RPE cells, A $\beta$ (1-40) and $A \beta(1-42)$ can stimulate the expression of tolllike receptor 4 and Rel proteins and activate the nuclear factor- $\mathrm{\kappa B}(\mathrm{NF}-\kappa \mathrm{B})$ signalling pathway. ${ }^{23}{ }^{24}$ Activation of this pathway can upregulate the expression of proinflammatory cytokines, such as interleukin (IL)-6, tumour necrosis factor $\alpha$ (TNF- $\alpha)$, IL-1 $\beta$, IL-18, which results in the event of nucleotide-binding oligomerisation domainlike receptors family pyrin domain containing 3 (NLRP3) inflammasome activity, and other apoptotic factors in the choroid and the neuroretina. ${ }^{23} 2526$ Prolonged NLRP3 inflammasome activity induced by $\mathrm{A} \beta$ via nicotinamide adenine dinucleotide phosphate (NADPH) oxidase and mitochondria-dependent reactive oxygen species (ROS) production leads to mitochondrial DNA damages, which eventually activates pyroptosis and apoptosis in RPE cells. ${ }^{27} 28$ Thus, the suppression of NLRP3 inflammasome activation may decrease the inflammation in RPE cells. ${ }^{29}$ Also, a new finding has illustrated that $A \beta(1-42)$ can activate primary microglial, which results in the overproduction of proinflammatory cytokines, such as IL-1 $\beta$ and cyclooxygenase-2 (cox-2), and exacerbate the deterioration of visual function and PRCs apoptosis. ${ }^{30}$ Moreover, the activation of liver $\mathrm{X}$ receptor $\alpha$ (LXR $\alpha)$ and ATP binding cassette subfamily A member 1 (ABCA1) downregulates the expressions of proinflammatory cytokines, such as IL- 6 and TNF- $\alpha$, and suppresses the A $\beta$-induced inflammatory activity and senescent responses in RPE cells. ${ }^{31}$ Intravitreal injection of oligomeric $A \beta$ suppresses the protein expressions of LXR $\alpha$ and ABCA1, which provokes inflammatory activity by upregulation of proinflammatory cytokines. ${ }^{32}$ Several medical agents, such as Brimonidine, Puerarin and Baicalin, have been shown to alleviate intracellular pyroptosis and viability damage through preventing $\mathrm{A} \beta$-induced oxidative stress damage and inflammatory activity. ${ }^{33-35}$ Also, sirtuin 1 (SIRT1) has been identified as a protective factor, which suppresses the activation of NF- $\mathrm{KB}$ signalling pathway induced by $\mathrm{A} \beta$ in AMD. ${ }^{36}$ These results have shown the proinflammatory role of $\mathrm{A} \beta$ in $\mathrm{AMD}$.

\section{$A \beta$ induces mitochondrial dysfunction in AMD}

In AMD, $A \beta$ dysregulates the level of mitochondriaassociated proteins, such as pyruvate dehydrogenase and the electron transport chain complex IV, and disrupts the translocation of hydrogen from the matrix to the intermembrane space, which results in abnormal mitochondrial electrical activity and ROS increase. ${ }^{37}{ }^{38}$ These aberrant activities could induce alterations in mitochondrial DNA and mitochondrial lipids, leading to mitochondrial impairment. ${ }^{37}{ }^{38}$ Previous study has indicated that mitochondrial oxidative phosphorylation is inhibited by $\mathrm{A} \beta$ in $\mathrm{AD} .{ }^{39}$ Recent study has shown mitochondrial impairment in AMD accompanied along with oxidative phosphorylation. ${ }^{40}$ The level of proteins related to the oxidative phosphorylation and mitochondrial dysfunction, such as Ndufs4 and Atp6vlg1, has been significantly downregulated in the initial stage of $A \beta$ exposure and recovered after 24-hour exposure of $A \beta$ in $661 \mathrm{~W}$ cone PRCs. ${ }^{40}$ This mechanism is regulated by sirtuin signalling pathway, which has been shown to be involved in neuroprotection against toxicity in retina, ${ }^{41}$ and also tau protein, which is thought to be coexisted with $A \beta^{42}$ and cause the suppression of oxidative phosphorylation. ${ }^{39}$ Tau protein in accumulation with $A \beta$ induces the decline in oxidative phosphorylation in early stage of AMD. ${ }^{40}$ Moreover, under the presence of transcription factor PU.1/SPI1 induced by A, NADPH oxidase activation occurs and induces the expression of NADPH oxidase (NOX) complex, such as NOX4-p22 $2^{\text {phox }}$ complex, leading to the outcome of mitochondrial dysfunction and excessive oxidative stress in RPE cells. ${ }^{43}$ Silencing of PU.1/SPI has been shown to impede the process of ROS production and mitochondrial dysfunction and protect the retinal structure and function from oxidative damage. ${ }^{43}$ This novel finding brings out new insight into preventing mitochondrial dysfunction induced by A $\beta$ in RPE cells. From above, it is suggested that $A \beta$ could lead to the consequence of mitochondrial dysfunction in AMD.

\section{$A \beta$ alters the function of ribosome in AMD}

In initial stage of AMD, ribosomal protein synthesis has been aberrantly altered. Protein translation initiation factors, eIF2 $\alpha$, eIF3 $\eta$ and eIF5, and elongation factor, eEF2, are abnormally regulated, which induces ribosomal dysfunction in AMD. ${ }^{44}$ In recent study, ribosomal proteins are downregulated in the initial stage of the neurotoxicity induced by $\mathrm{A} \beta$ in AMD. ${ }^{40}$ Interestingly, after 24-hour treatment with $\mathrm{A} \beta$, ribosomal proteins, such as Rpl29 and Rps19, are alleviated to its normal level in $661 \mathrm{~W}$ cells. ${ }^{40}$ Meanwhile, it has been demonstrated that the differential effect of $A \beta$ may be due to the recuperation of PRCs from oxidative stress. ${ }^{40}$ Thus, ribosomal proteins are negatively influenced in the early stage of the toxicity induced by $\mathrm{A} \beta$ treatment in AMD.

\section{$A \beta$ regulates the lysosomal pathway in AMD}

Autophagy-lysosomal pathway has been elucidated to be a remarkable mechanism to prevent the accumulation of $A \beta$ in the intracellular space in AMD. ${ }^{45}$ Previously, autophagy has been reported to be significantly involved in the process of $A \beta$ clearance and degradation due to its property of clearing proteins. Successive autophagy activity could inhibit the accumulation of deleterious proteins, preventing the degeneration of RPE cells and decelerating the ageing process. ${ }^{46}$ In fact, $A \beta$ could induce autophagy in RPE, which forms resistance to the formation of $\mathrm{A} \beta$ deposition, but the underlying molecular mechanisms are still unclear, which needs to be further explored. ${ }^{47}$ Previous findings have proved that autophagy-lysosomal system maintains retinal homeostasis and prevents retinal degeneration in AMD. ${ }^{48}$ Recent 
research has observed that lysosomal proteins are upregulated in the early stage of $A \beta$ treatment, which protects cells from $A \beta$ aggregation. ${ }^{40}$ However, after 24-hour $A \beta$ exposure, lysosomal proteins are subtly downregulated, which indicates that $A \beta$ might accumulate after long $A \beta$ exposure. ${ }^{40}$ This has also been proved by a new research which found that $A \beta$ accumulates in lysosomes under the circumstances of late-endocytic compartments and damages the function of RPE cells chronically. ${ }^{49}$ From this information, self-protection is induced through activating the autophagy-lysosomal pathway in the initial stage of $A \beta$ exposure, ${ }^{40}$ rather than in the late stage.

\section{A $\beta$ affects RNA splicing in AMD}

Spliceosome, a ribonucleoprotein (RNP) complex, comprising small nuclear RNAs (snRNA) and numerous proteins, has a significant role in the process of pre-mRNA splicing. ${ }^{50}$ Defects of mRNA processing and splicing are detected in $\mathrm{AD}$ according to previous research. ${ }^{51}$ Previous studies have also reported that the alterations in ubiquitous core snRNP proteins, pre-mRNA processing factor 3 (PRPF3), and splicing factor, retinitis pigmentosa 9, induce the aggregation of misfolded proteins, such as T494M mutant PRPF3, in PRCs, and lead to retinal degeneration. ${ }^{52}$ Recent finding has shown that, in the initial stage of $\mathrm{A} \beta$ treatment, several snRNP proteins reveal no change or subtle downregulation in PRCs. However, after 24-hour treatment with higher A $\beta$ concentrations, proteins, such as Acin1 and Rbmx, are upregulated, which presents that aberrant alterations in RNA splicing is induced at a chronic exposure to $A \beta .^{40}$ Thus, RNA splicing in AMD is abnormally influenced in late stage of $A \beta$ exposure. ${ }^{40}$

\section{A $\beta$ modulates angiogenesis in AMD}

Angiogenesis has been thought to be induced by the imbalance of angiogenesis-related factors. ${ }^{54}$ In AMD, vascular endothelial growth factor (VEGF) is highly expressed in subfoveal fibrovascular membrane, the surrounding tissue and the RPE cells, which stimulates the growth of new blood vessels in the subretinal region. ${ }^{55}$ Under the condition of low concentration of $A \beta$, RPE cells secrete significant level of pigment epithelium-derived factor (), an antiangiogenetic factor, through $A \beta$-receptor for advanced glycation endproducts pathway, which inhibits the apoptotic pathway leading to RPE cell growth. ${ }^{56}$ However, high concentration of $\mathrm{A} \beta$ treatment induces high expression of mRNA of VEGF in

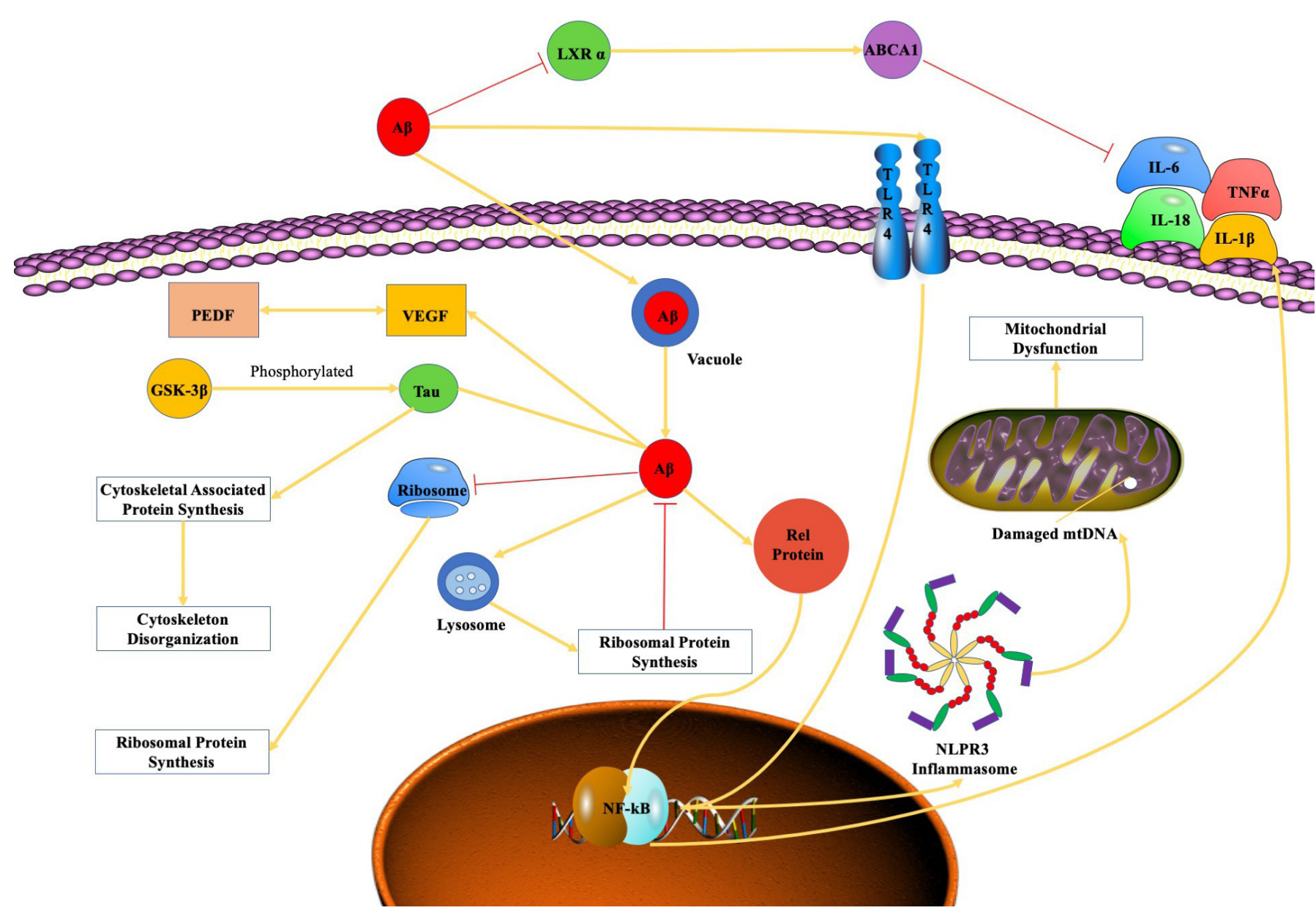

Figure 1 The mechanistic pathwayof amyloid $\beta$-peptide in AMD. A $\beta$, amyloid $\beta$-peptide; AMD, age-related macular degeneration; GSK3 $\beta$, glycogen synthase kinase 3 beta; IL, interleukin; LXR $\alpha$, liver X receptor $\alpha$; NF- $\kappa B$, nuclear factor- $\kappa B$; PEDF, pigment epithelium derived factor; VEGF, vascular endothelial growth factor. 
RPE cells and increases the death of RPE cells. ${ }^{56}$ Moreover, A $\beta$-induced mitochondrial ROS have been shown to promote the production of $A \beta$-stimulated angiogenic factor in ARPE-19 cells. ${ }^{57}$ These findings have shown that $\mathrm{A} \beta$ could regulate angiogenesis-related factors. Due to the accumulation of $A \beta$ in AMD, it is speculated that $A \beta$ could cause the growth of new blood vessels, which needs to be further explored.

\section{$A \beta$ alters actin cytoskeleton in AMD}

Previous research has shown that $A \beta$ can stimulate the loss of actin cytoskeleton integrity and function through abnormal phosphorylation events which induces microtubules instability and actin dynamics imbalance in $\mathrm{AD}{ }^{58}$ Recent findings suggest that accumulation of $A \beta$ in intracellular region can also induce disorganisation of actin cytoskeleton and disruption of tight junction via NF- $\mathrm{BB}$ activation in AMD. ${ }^{40}$ Subretinally injected $\mathrm{A} \beta$ dislocates occludin and decreases the levels of occludin and zonula occludens-1 mRNA expression in RPE cells. ${ }^{60}$ This molecular alteration destabilises the link between transmembrane and actin cytoskeleton and influences the transepithelial permeability of RPE cells. ${ }^{60}$ Recent findings have also shown that Tau, a microtubule-associated protein, is highly phosphorylated by the activation of glycogen synthase kinase 3 beta (GSK3 $\beta$ ) in response to high concentration $\mathrm{A} \beta$ treatment, which upregulates the expression of cytoskeleton-associated proteins and induces reorganisation of cytoskeleton networks in PRCs. ${ }^{40}$ GSK3 $\beta$ inhibition has been observed in the early stages of $A \beta$ exposure, which indicates the countering activity of the PRCs in response to A $\beta$-induced neurotoxicity. ${ }^{40}$ Moreover, keratins, intermediate filament proteins, are remarkably enriched in early timepoint and return to normal level after prolonged (24hours) $A \beta$ treatment in $661 \mathrm{~W}$ cells, which suggests that keratin filaments are significantly influenced in early $A \beta$ treatment. ${ }^{40}$ From above, it is suggested that $A \beta$ could disorganise the cytoskeleton in RPE cells and PRCs in AMD.

\section{Protective role of targeting $A \beta$ in AMD}

The approach to decrease or eliminate the accumulation of $A \beta$ in the subretinal region has been imperatively developed in order to inhibit inflammatory activity and prevent visual loss efficiently. Evidence has shown that immunotherapeutic strategies, such as anti-A $\beta$ antibodies treatment, could reduce neuronal damages in the retina and may recover the visual function. ${ }^{61}$ Moreover, anti-A $\beta$ monoclonal antibody treatment can lead to the reduction of $\mathrm{A} \beta$ deposition and deactivates the plasma proteins in the complement system, which prevents or reverses the loss of eye vision. ${ }^{6162}$ Previous research has reported that the mutation and loss-of-function of the triggering receptor expressed in myeloid/microglial cells-2 (TREM2) could negatively impact the efficiency of $\mathrm{A} \beta$ clearance. ${ }^{63}$ However, with incubating anti-miRNA-34a, TREM2 can be restored back to the normal homeostatic level, which recovers the ability to eliminate $A \beta .^{63}$ Moreover, when
NF- $\mathrm{KB}$ pathway induces and upregulates the expression of miRNA-34a, downregulation of TREM2 expression has been observed in human AMD ${ }^{63}$ Thus, the discovered finding of NF-KB regulated, miRNA-34a-mediated TREM2 sensor-receptor circuit give novel thought about the utilisation of anti-NF- $\mathrm{BB}$ and anti-miRNA-based therapeutic strategies to clear $A \beta$ deposits. ${ }^{63}$ Moreover, previous findings have shown that the possible reason for increasing amount of $A \beta$ in the senescent models is the curtailment in the expression of neprilysin level and the growing activity of beta-secretase-1 leading to the higher level of $A \beta$ synthesis in the RPE cells. ${ }^{6465}$ Recent research has shown that intravitreal injections of neprilysin in mice model with AMD have shown the reduction of $A \beta$ accumulation, which represents a potential method to slow down the development of AMD pathogenesis. ${ }^{66}$

Up-to-date research has recently revealed that fucoxanthin, an orange-coloured pigment presented in brown seaweeds, plays a momentous potential in inhibiting the pathogenesis of oxidative stress-induced AMD ${ }^{67}$ Pretreatment of fucoxanthin significantly suppresses oxidative stress by reducing ROS and malondialdehyde concentration, nuclear phosphorylated histone deposition and production of senescence-associated $\beta$ galactosidase. ${ }^{67}$ Compared with control group, pretreated groups have shown less $A \beta$ deposition, low expression of beta-site APP-cleaving enzyme 1 and the prevention of tight junction disruption. ${ }^{67}$

These new discoveries could eventually impede $A \beta$-induced ROS production and oxidative stress and other $\mathrm{A} \beta$-induced injuries in retina cells and also broaden the potential for curing exudative and non-exudative AMD in the future.

\section{CONCLUSION}

A $\beta$-induced inflammatory activity, ribosomal dysfunction, oxidative phosphorylation dysregulation, spliceosome impairment, angiogenesis and cytoskeleton destabilisation cause numerous damages in the subretinal region, which is associated with the pathogenesis of AMD (figure 1). Future research on the molecular mechanism of $A \beta$-mediated pathogenesis of AMD may provide novel thoughts about potential therapies of AMD related to $\mathrm{A} \beta$.

Contributors MW carried out the searching and collection of publications and drafted the review manuscript. SS participated in collecting the related publications. SJ and XS revised the manuscript. JW, corresponding author, designed and revised the manuscript.

Funding This manuscript was supported by National Natural Science Foundation of China (No. 82070961); Sanming Project of Medicine in Shenzhen (SZSM201812091); International Science and Technology Cooperation Research Project of Shenzhen Science and Technology Innovation Committee (GJHZ20190929145402153).

Competing interests None declared.

Patient consent for publication Not required.

Provenance and peer review Not commissioned; internally peer reviewed.

Open access This is an open access article distributed in accordance with the Creative Commons Attribution Non Commercial (CC BY-NC 4.0) license, which permits others to distribute, remix, adapt, build upon this work non-commercially, 
and license their derivative works on different terms, provided the original work is properly cited, appropriate credit is given, any changes made indicated, and the use is non-commercial. See: http://creativecommons.org/licenses/by-nc/4.0/.

ORCID iD

Minwei Wang http://orcid.org/0000-0003-4430-8894

\section{REFERENCES}

1 Rasoulinejad SA, Zarghami A, Hosseini SR, et al. Prevalence of agerelated macular degeneration among the elderly. Caspian J Intern Med 2015:6:141-7.

2 Javitt JC, Zhou Z, Maguire MG, et al. Incidence of exudative age-related macular degeneration among elderly Americans. Ophthalmology 2003;110:1534-9.

3 Klein R, Klein BE, Jensen SC, et al. The five-year incidence and progression of age-related maculopathy: the Beaver dam eye study. Ophthalmology 1997;104:7-21.

4 Mitchell P, Smith W, Attebo K, et al. Prevalence of age-related maculopathy in Australia. the blue Mountains eye study. Ophthalmology 1995;102:1450-60.

5 Feng $L$, Cao L, Zhang Y, et al. Detecting $A \beta$ deposition and RPE cell senescence in the retinas of SAMP8 mice. Discov Med 2016;21:149-58

6 Vassar R, Bennett BD, Babu-Khan S, et al. Beta-secretase cleavage of Alzheimer's amyloid precursor protein by the transmembrane aspartic protease BACE. Science 1999;286:735-41.

7 Takasugi N, Tomita T, Hayashi I, et al. The role of presenilin cofactors in the $\gamma$-secretase complex. Nature 2003;422:438-41.

8 Taylor-Walker G, Lynn SA, Keeling E, et al. The Alzheimer's-related amyloid beta peptide is internalised by R28 neuroretinal cells and disrupts the microtubule associated protein 2 (MAP-2). Exp Eye Res 2016;153:110-21.

9 Murphy MP, LeVine H. Alzheimer's disease and the amyloid-beta peptide. J Alzheimers Dis 2010;19:311-23.

10 Biscetti L, Luchetti E, Vergaro A, et al. Associations of Alzheimer's disease with macular degeneration. Front Biosci 2017;9:174-91.

11 Masuzzo A, Dinet V, Cavanagh C, et al. Amyloidosis in retinal neurodegenerative diseases. Front Neurol 2016;7:127.

12 Dentchev T, Milam AH, Lee VM-Y, et al. Amyloid-Beta is found in drusen from some age-related macular degeneration retinas, but not in drusen from normal retinas. Mol Vis 2003:9:184-90.

13 Anderson DH, Talaga KC, Rivest AJ, et al. Characterization of beta amyloid assemblies in drusen: the deposits associated with aging and age-related macular degeneration. Exp Eye Res 2004;78:243-56.

14 Ong SS, Proia AD, Whitson HE, et al. Ocular amyloid imaging at the crossroad of Alzheimer's disease and age-related macular degeneration: implications for diagnosis and therapy. J Neurol 2019;266:1566-77.

15 Liu C, Cao L, Yang S, et al. Subretinal injection of amyloid- $\beta$ peptide accelerates RPE cell senescence and retinal degeneration. Int $\mathrm{J} \mathrm{Mol}$ Med 2015;35:169-76.

16 Prasad T, Zhu P, Verma A, et al. Amyloid $\beta$ peptides overexpression in retinal pigment epithelial cells via AAV-mediated gene transfer mimics AMD-like pathology in mice. Sci Rep 2017;7:3222.

17 Schmidt M, Sachse C, Richter W, et al. Comparison of Alzheimer Abeta(1-40) and Abeta(1-42) amyloid fibrils reveals similar protofilament structures. Proc Natl Acad Sci U S A 2009;106:19813-8.

18 Curcio CA. Soft drusen in age-related macular degeneration: biology and targeting via the oil spill strategies. Invest Ophthalmol Vis Sci 2018;59:AMD160-81.

19 Yoshida T, Ohno-Matsui K, Ichinose S, et al. The potential role of amyloid beta in the pathogenesis of age-related macular degeneration. J Clin Invest 2005;115:2793-800.

20 Castaño EM, Prelli F, Soto C, et al. The length of amyloid-beta in hereditary cerebral hemorrhage with amyloidosis, dutch type. Implications for the role of amyloid-beta 1-42 in Alzheimer's disease. J Biol Chem 1996;271:32185-91.

21 Kauppinen A, Paterno JJ, Blasiak J, et al. Inflammation and its role in age-related macular degeneration. Cell Mol Life SCl 2016;73:1765-86

22 Wang Y, Wang VM, Chan C-C. The role of anti-inflammatory agents in age-related macular degeneration (AMD) treatment. Eye 2011;25:127-39.

23 Chen L, Bai Y, Zhao M, et al. TIr4 inhibitor attenuates amyloid- $\beta$ induced angiogenic and inflammatory factors in ARPE-19 cells: implications for age-related macular degeneration. Mol Med Rep 2016;13:3249-56.
24 Sun J, Huang P, Liang J, et al. Cooperation of Rel family members in regulating $A \beta_{1-40}$-mediated pro-inflammatory cytokine secretion by retinal pigment epithelial cells. Cell Death Dis 2017;8:e3115.

25 Liu RT, Gao J, Cao S, et al. Inflammatory mediators induced by amyloid-beta in the retina and RPE in vivo: implications for inflammasome activation in age-related macular degeneration. Invest Ophthalmol Vis Sci 2013;54:2225-37.

26 Liu RT, Wang A, To E, et al. Vinpocetine inhibits amyloid-beta induced activation of NF- $\mathrm{BB}$, NLRP3 inflammasome and cytokine production in retinal pigment epithelial cells. Exp Eye Res 2014;127:49-58

27 Gao J, Cui JZ, To E, et al. Evidence for the activation of pyroptotic and apoptotic pathways in RPE cells associated with NLRP3 inflammasome in the rodent eye. J Neuroinflammation 2018;15:15.

28 Wang K, Yao Y, Zhu X, et al. Amyloid $\beta$ induces NLRP3 inflammasome activation in retinal pigment epithelial cells via NADPH oxidase- and mitochondria-dependent ROS production. $J$ Biochem Mol Toxicol 2017;31:e21887.

29 Zhao T, Gao J, Van J, et al. Age-Related increases in amyloid beta and membrane attack complex: evidence of inflammasome activation in the rodent eye. J Neuroinflammation 2015;12:121.

30 Wu J, Gao G, Shi F, et al. Activated microglia-induced neuroinflammatory cytokines lead to photoreceptor apoptosis in A $\beta$-injected mice. J Mol Med 2021;99:713-28.

31 Dai B, Lei C, Lin R, et al. Activation of liver X receptor $\alpha$ protects amyloid $\beta_{1-40}$ induced inflammatory and senescent responses in human retinal pigment epithelial cells. Inflamm Res 2017;66:523-34

32 Lei $\mathrm{C}$, Lin R, Wang J, et al. Amelioration of amyloid $\beta$-induced retinal inflammatory responses by a LXR agonist TO901317 is associated with inhibition of the NF- $\mathrm{KB}$ signaling and NLRP3 inflammasome. Neuroscience 2017;360:48-60.

33 Tsao SW, Gabriel R, Thaker K. Effects of brimonidine on retinal pigment epithelial cells and Müller cells exposed to amyloid-beta 1-42 peptide in vitro. Ophthalmic Surg 2018;49:23-8.

34 Wang $\mathrm{K}$, Zhu X, Zhang $\mathrm{K}$, et al. Puerarin inhibits amyloid $\beta$-induced NLRP3 inflammasome activation in retinal pigment epithelial cells via suppressing ROS-dependent oxidative and endoplasmic reticulum stresses. Exp Cell Res 2017;357:335-40.

35 Sun $\mathrm{H}-\mathrm{J}$, Jin X-M, Xu J, et al. Baicalin alleviates age-related macular degeneration via miR-223/NLRP3-regulated pyroptosis. Pharmacology 2020;105:28-38.

36 Cao L, Liu C, Wang F, et al. Sirt1 negatively regulates amyloid-betainduced inflammation via the NF-кB pathway. Braz J Med Biol Res 2013;46:659-69.

37 Eckert A, Schmitt K, Götz J. Mitochondrial dysfunction - the beginning of the end in Alzheimer's disease? Separate and synergistic modes of tau and amyloid- $\beta$ toxicity. Alzheimers Res Ther 2011;3:15.

38 Pagani L, Eckert A. Amyloid-Beta interaction with mitochondria. Int $J$ Alzheimers Dis 2011;2011:1-12.

39 Rhein V, Song X, Wiesner A, et al. Amyloid-Beta and tau synergistically impair the oxidative phosphorylation system in triple transgenic Alzheimer's disease mice. Proc Natl Acad Sci U S A 2009;106:20057-62.

40 Deng L, Pushpitha K, Joseph C, et al. Amyloid $\beta$ induces early changes in the ribosomal machinery, cytoskeletal organization and oxidative phosphorylation in retinal photoreceptor cells. Front $\mathrm{Mol}$ Neurosci 2019;12:24.

41 Ban N, Ozawa Y, Osada H, et al. Neuroprotective role of retinal SIRT3 against acute photo-stress. NPJ Aging Mech Dis 2017;3:19.

42 Huang $\mathrm{H}-\mathrm{C}$, Jiang Z-F. Accumulated amyloid-beta peptide and hyperphosphorylated tau protein: relationship and links in Alzheimer's disease. J Alzheimers Dis 2009;16:15-27.

43 Sun J, Chen J, Li T, et al. ROS production and mitochondrial dysfunction driven by PU.1-regulated NOX4-p22 ${ }^{\text {phox }}$ activation in $A \beta$-induced retinal pigment epithelial cell injury. Theranostics 2020;10:11637-55

44 Hernández-Ortega K, Garcia-Esparcia P, Gil L, et al. Altered machinery of protein synthesis in Alzheimer's: from the nucleolus to the ribosome. Brain Pathol 2016;26:593-605.

45 Tarasoff-Conway JM, Carare RO, Osorio RS, et al. Clearance systems in the brain-implications for Alzheimer disease. Nat Rev Neurol 2015;11:457-70.

46 Amadio M, Kaarniranta K, Xu H, et al. Molecular mechanisms underlying age-related ocular diseases. Oxid Med Cell Longev 2018;2018:1-2.

47 Feng L, Liao X, Zhang Y, et al. Protective effects on age-related macular degeneration by activated autophagy induced by amyloid- $\beta$ in retinal pigment epithelial cells. Discov Med 2019;27:153-60. 
48 Sinha D, Valapala M, Shang P, et al. Lysosomes: regulators of autophagy in the retinal pigmented epithelium. Exp Eye Res 2016;144:46-53.

49 Lynn SA, Johnston DA, Scott JA, et al. Oligomeric $A \beta_{1-42}$ Induces an AMD-Like Phenotype and Accumulates in Lysosomes to Impair RPE Function. Cells 2021;10:413.

50 Will CL, Lührmann R. Spliceosome structure and function. Cold Spring Harb Perspect Biol 2011;3:a003707.

$51 \mathrm{Ke} \mathrm{YD,} \mathrm{Ke} \mathrm{Y,} \mathrm{Dramiga} \mathrm{J,} \mathrm{et} \mathrm{al.} \mathrm{Tau-mediated} \mathrm{nuclear} \mathrm{depletion}$ and cytoplasmic accumulation of SFPQ in Alzheimer's and Pick's disease. PLoS One 2012;7:e35678.

52 Comitato A, Spampanato C, Chakarova C, et al. Mutations in splicing factor PRPF3, causing retinal degeneration, form detrimental aggregates in photoreceptor cells. Hum Mol Genet 2007;16:1699-707.

53 Růžičková Šárka, Staněk D. Mutations in spliceosomal proteins and retina degeneration. RNA Biol 2017;14:544-52.

54 Ohno-Matsui K, Morita I, Tombran-Tink J, et al. Novel mechanism for age-related macular degeneration: an equilibrium shift between the angiogenesis factors VEGF and PEDF. J Cell Physiol 2001;189:323-33.

55 Kvanta A, Algvere PV, Berglin L, et al. Subfoveal fibrovascular membranes in age-related macular degeneration express vascular endothelial growth factor. Invest Ophthalmol Vis Sci 1996;37:1929-34.

56 Masuda N, Tsujinaka $\mathrm{H}$, Hirai $\mathrm{H}$, et al. Effects of concentration of amyloid $\beta(A \beta)$ on viability of cultured retinal pigment epithelial cells. BMC Ophthalmol 2019;19:70.

57 Wu L, Tan X, Liang L, et al. The role of mitochondria-associated reactive oxygen species in the amyloid $\beta$ induced production of angiogenic factors B Y ARPE-19 cells. Curr Mol Med 2017;17:140-8.

58 Henriques AG, Oliveira JM, Carvalho LP, et al. A $\beta$ influences cytoskeletal signaling cascades with consequences to Alzheimer's disease. Mol Neurobiol 2015;52:1391-407.
59 Jo DH, Cho CS, Kim JH, et al. Intracellular amyloid- $\beta$ disrupts tight junctions of the retinal pigment epithelium via NF- $\kappa \mathrm{B}$ activation. Neurobiol Aging 2020;95:115-22.

60 Bruban J, Glotin A-L, Dinet V, et al. Amyloid-beta(1-42) alters structure and function of retinal pigmented epithelial cells. Aging Cell 2009;8:162-77.

61 Ding J-D, Johnson LV, Herrmann R, et al. Anti-Amyloid therapy protects against retinal pigmented epithelium damage and vision loss in a model of age-related macular degeneration. Proc Natl Acad Sci U S A 2011;108:E279-87.

62 Catchpole I, Germaschewski V, Hoh Kam J, et al. Systemic administration of Abeta mAb reduces retinal deposition of Abeta and activated complement $\mathrm{C} 3$ in age-related macular degeneration mouse model. PLoS One 2013;8:65518.

63 Bhattacharjee S, Zhao Y, Dua P, et al. MicroRNA-34a-mediated down-regulation of the microglial-enriched triggering receptor and phagocytosis-Sensor TREM2 in age-related macular degeneration. PLoS One 2016;11:e0150211.

64 Wang J, Ohno-Matsui K, Morita I. Elevated amyloid $\beta$ production in senescent retinal pigment epithelium, a possible mechanism of subretinal deposition of amyloid $\beta$ in age-related macular degeneration. Biochem Biophys Res Commun 2012;423:73-8.

65 Hersh LB, Rodgers DW. Neprilysin and amyloid beta peptide degradation. Curr Alzheimer Res 2008;5:225-31.

66 Parthasarathy R, Chow KM, Derafshi Z, et al. Reduction of amyloid-beta levels in mouse eye tissues by intra-vitreally delivered neprilysin. Exp Eye Res 2015;138:134-44.

67 Chen S-J, Lin T-B, Peng H-Y, et al. Cytoprotective potential of fucoxanthin in oxidative stress-induced age-related macular degeneration and retinal pigment epithelial cell senescence in vivo and in vitro. Mar Drugs 2021;19:114. 